\title{
Analisis Strategi Pemasaran untuk Meningkatkan Jumlah Iklan (Studi Kasus pada Radio Kanjuruhan FM)
}

\author{
Ike Ratnasari ${ }^{1}$ \\ Anggraini Wijayanti ${ }^{2}$ \\ Program Studi Manajemen \\ Sekolah Tinggi Ilmu Ekonomi Kertanegara Malang \\ e-mail : ratnamnz.ir@gmail.com
}

\begin{abstract}
The large amount of competition makes radio stations provide innovation as a form of marketing strategy to attract listeners and advertisers. In order to maintain the viability of its business, an effective marketing strategy is needed. One effort to find out the right marketing strategy for the company is to use a SWOT analysis. The purpose of this research is to find out the marketing strategies used and what should have been used Radio Kanjuruhan FM so far in increasing the number of advertisements. The marketing strategy carried out by Radio Kanjuruhan FM is a marketing mix that includes 4 components, namely, product, price, place, promotion. These 4 components provide an important role in supporting the progress of Radio Kanjuruhan FM. Based on the SWOT Radio Analysis Kanjuruhan FM can increase promotions, collaborate with local radio, increase the number of employees, utilize technology, and provide competitive prices. Whereas from the marketing strategy which includes, market segmentation, setting the target market (market targeting) and positioning (positioning) of Kanjuruhan FM Radio can find out which market segments have been listening to Radio Kanjuruhan FM.
\end{abstract}

Keywords : Marketing Strategic, SWOT Analysis

\begin{abstract}
Abstrak
Banyaknya persaingan membuat stasiun-stasiun radio memberikan inovasi sebagai bentuk strategi pemasaran untuk memikat pendengar dan pengiklan. Agar dapat mempertahankan kelangsungan hidup usahanya, maka diperlukan strategi pemasaran yang efektif. Salah satu upaya untuk dapat mengetahui strategi pemasaran yang tepat bagi perusahaan adalah dengan menggunakan analisis SWOT. Tujuan dalam penelitian ini adalah Untuk mengetahui strategi pemasaran yang digunakan dan yang seharusnya digunakanRadio Kanjuruhan FM selama ini dalam meningkatkan jumlah iklan. Strategi pemasaran yang dilaksanakan Radio Kanjuruhan FM adalah bauran pemasaran yang meliputi 4 komponen yaitu, product, price, place, promotion. 4 komponen tersebut memberikan peranan penting dalam menunjang kemajuan Radio Kanjuruhan FM. Berdasarkan Analisis SWOT Radio Kanjuruhan FM bisa memperbanyak promosi, melakukan kerja sama dengan radio local, menambah jumlah pegawai, memanfaatkan teknologi, dan memberikan harga yang kompetitif. Sedangkan dari strategi pemasaran yang diantaranya, segmentasi pasar, menetapkan pasar sasaran (market targetting) dan penentuan posisi pasar (positioning) Radio Kanjuruhan FM bisa mengetahui segmentasi pasar mana saja yang selama ini mendengarkan Radio Kanjuruhan FM
\end{abstract}

Kata kunci : strategi pemasaran, analisis SWOT 


\section{I.PENDAHULUAN}

Pada era digital seperti sekarang ini media komunikasi sangatlah diperlukan. Di indonesia terdapat berbagai jenis media komunikasi untuk menyebarkan informasi, antara lain televisi, radio, surat kabar, internet, dan lain-lain. Banyaknya teknologi baru yang bermunculan, akan menggeser teknologi yang dirasa sudah ada pembaharuannya. Radio merupakan salah satu teknologi yang digunakan untuk mengirimkan sinyal dengan gelombang tertentu, atau dikenal dengan gelombang elektromagnetik yang merupakan hasil modulasi dan radiasi dari elektromagnetik. Radio ite dimanfaatkan sebagai alat penyampai informasi dari berbagai sumber. Banyaknya persaingan membuat stasiunstasiun radio memberikan inovasi sebagai bentuk strategi pemasaran untuk memikat pendengar dan pengiklan. Agar dapat mempertahankan kelangsungan hidup usahanya, maka diperlukan peamasaran yang efektif. Untuk itu strategi pemasaran (Kotler, 2008) adalah pola ite yang akan digunakan untuk mencapai tujuan pemasaran pada suatu perusahaan, ite mengenai startegi spesifik untuk pasar sasaran, penetapan posisi, bauran pemasaran (marketing mix), dan besarnya sebuah pengeluaran pemasaran. Salah satu upaya untuk dapat mengetahui strategi pemasaran yang tepat bagi perusahaan adalah dengan menggunakan analisis SWOT (fahmi, 2015).

Salah satu radio di kabupaten Malang adalah Kanjuruhan FM yang memiliki pendengar cukup banyak, itera di seluruh Kabupaten Malang. Sayangnya, ada beberapa hal yang membuat Radio Kanjuruhan FM tidak ite diterima oleh masyarakat dibeberapa daerah. Seperti pencapaian frekuensi yang terbatas sehingga masyarakat yang berada di tengah kota maupun diperbatasan tidak ite mendengar Radio Kanjuruhan FM. Selain itu, internet yang kini mulai dipakai oleh sebagian masyarakat untuk kebutuhannya juga dimanfaatkan Radio Kanjuruhan FM seperti Radio Streaming sebagai salah satu cara untuk menarik pendengar. selain itu, Kanjuruhan FM perlu membuat inovasi sebagai cara untuk meningkatkan jumlah iklan. Hal ini dikarenakan masuknya iklan yang ada berfluktuatif, ditunjukkan pada tabel 1.

Tabel 1. Jumlah Iklan

\begin{tabular}{cc}
\hline Tahun & Jumlah Iklan \\
\hline 2014 & 38 \\
2015 & 34 \\
2016 & 37 \\
\hline
\end{tabular}

Sumber: Kanjuruhan FM 2018

Berdasarkan uraian latar belakang diatas, peneliti tertarik untuk melakukan sebuah penelitian dengan judul "Analisis Strategi Pemasaran untuk Meningkatkan Jumlah Iklan (Studi Kasus pada Radio Kanjuruhan FM)". 


\section{A. Rumusan Masalah}

Berdasarkan latar belakang maka masalah dalam penelitian ini dapat dirumuskan sebagai berikut :

1) Bagaimana strategi pemasaran yang digunakan Radio Kanjuruhan FM untuk meningkatkan jumlah iklan?

2) Bagaimanakah strategi yang perlu dilakukan Radio Kanjuruhan FM di masa yang akan itera?

\section{B. Tujuan Penelitian}

Adapun tujuan dalam penelitian ini adalah :

1) Untuk mengetahui strategi pemasaran yang digunakan Radio Kanjuruhan FM selama ini dalam meningkatkan jumlah iklan.

2) Untuk mengetahui strategi pemasaran yang seharusnya dilakukan Radio Kanjuruhan FM dalam meningkatkan jumlah iklan di masa yang akan itera.

\section{METODE}

\section{A. Jenis dan Sumber Data}

Peniliti membutuhkan sejumlah data yang mendukung baik yang berasal dari dalam perusahaan maupun dari luar perusahaan dalam hal ini Radio Kanjuruhan FM. Penelitian menggunakan pendekatan kualitatif yang bertujuan untuk mengumpulkan data berupa kata-kata tertulis atau lisan dan perilaku dari orang-orang yang diamati.

1) Data Primer

Data primer merupakan data yang diperoleh dari penelitian dilapangan. Peneliti menggunakan observasi yang sumbernya berasal dari admin.

2) Data Sekunder

Pengumpulan data yang dapat dijadikan pelengkap guna melancarkan proses penelitian. Data sekunder dilakukan melalui studi kepustakaan untuk mendapatkan informasi dari iterature-literatur yang berhubungan dengan judul, seperti makalah, majalah, buku, dan lain-lain.

\section{B. Teknik Pengumpulan Data}

1) Observasi

Peneliti melakukan penelitian secara langsung terhadap objek yang diteliti.

2) Indepth Interview (Wawancara Mendalam)

Penulis melakukan wawancara yang mendalam secara langsung dengan pihak yang dianggap mampu memberikan data dan berkompeten sesuai dengan permasalahan dalam penelitian. 


\section{Analisis data}

Analisis yang dilakukan dalam penelitian ini adalah menggunakan matrik SWOT merupakan alat pencocokan yang penting untuk membantu para manajer mengembangkan empat tipe strategi: Strategi SO (Strengths-Opportunities), Strategi WO (Weaknesses-Opportunities), Strategi ST (Strengths-Threats), dan Strategi WT (Weaknesses-Threats).

Tabel 2. Matrik SWOT

\begin{tabular}{|c|c|c|}
\hline E F I & $\begin{array}{c}\text { STRENGTH (S) } \\
\text { Faktor kekuatan internal }\end{array}$ & $\begin{array}{l}\text { WEAKNESSES } \\
\text { Faktor kelemahan internal }\end{array}$ \\
\hline OPPORTUNITIES (O) & Strategi SO & Strategi Wo \\
\hline $\begin{array}{l}\text { Faktor peluang } \\
\text { eksternal }\end{array}$ & $\begin{array}{l}\text { Daftar kekuatan untuk } \\
\text { meraih keuntungan dari } \\
\text { peluang yang ada }\end{array}$ & $\begin{array}{l}\text { Daftar untuk memperkecil } \\
\text { kelemahan dengan memanfaatkan } \\
\text { keuntungan dari peluang yang ada }\end{array}$ \\
\hline THREATS (T) & Strategi ST & Strategi WT \\
\hline $\begin{array}{c}\text { Faktor ancaman } \\
\text { eksternal }\end{array}$ & $\begin{array}{l}\text { Daftar kekuatan untuk } \\
\text { menghindari ancaman }\end{array}$ & $\begin{array}{l}\text { Daftar untuk memperkecil } \\
\text { kelemahan dan menghindari } \\
\text { ancaman }\end{array}$ \\
\hline
\end{tabular}

Sumber : Rangkuti, 2006

Berdasarkan Matriks SWOT diatas maka didapatkan 4 langkah strategi yaitu sebagai berikut :

1) Strategi SO

Strategi ini dibuat berdasarkan jalan pikiran perusahaan, yaitu dengan memanfaatkan seluruh kekuatan untuk merebut dan memanfaatkan peluang sebesar-besarnya. Strategi SO menggunakan kekuatan internal perusahaan untuk memanfaatkan peluang eksternal.

2) Strategi ST

Strategi ini menggunakan kekuatan yang dimiliki perusahaan untuk mengatasi ancaman. Strategi ST menggunakan kekuatan internal perusahaan untuk menghindari atau mengurangi dampak ancaman eksternal.

3) Strategi WO

Strategi ini diterapkan berdasarkan pemanfaatan peluang yang ada dengan cara meminimalkan kelemahan yang ada. Strategi WO bertujuan untuk memperbaiki kelemahan internal dengan memanfaatkan peluang eksternal. 
4) Strategi WT

Strategi ini didasarkan pada kegiatan yang bersifat defensif dan berusaha meminimalkan kelemahan serta menghindari ancaman. Strategi WT bertujuan untuk mengurangi kelemahan internal dengan menghindari ancaman eksternal.

Sedangkan Strategi Pemasaran

1) Segmentasi Pasar

Segmentasi pasar adalah membagi pasar menjadi pembeli yang kebutuhan, karakteristik atau perilakunya berbeda dan mungkin membutuhkan produk atau bauran pemasaran terpisah.

2) Menetapkan Pasar Sasaran (Market Targeting)

Pasar sasaran adalah sekelompok konsumen yang memiliki kebutuhan atau karakteristik yang sama yang ingin dilayani oleh perusahaan.

3) Penentuan Posisi Pasar (Postioning)

Positioning adalah suatu langkah perusahaan dalam memperkenalkan produknya kepada konsumen agar dapat menciptakan kesan-kesan tertentu dibenak konsumen, serta apa yang membedakan dengan produk pesaing.

\section{HASIL DAN PEMBAHASAN}

\section{A. Aspek Program Siaran}

Tabel 3. Jadwal Siaran Radio Kanjuruhan FM

\begin{tabular}{|c|c|c|c|c|c|c|c|}
\hline \multirow{2}{*}{ JAM } & \multicolumn{7}{|c|}{ HARI } \\
\hline & SENIN & SELASA & RABU & KAMIS & JUMAT & SABTU & MINGGU \\
\hline $\begin{array}{c}06.00- \\
07.00 \\
07.00- \\
08.00\end{array}$ & $\begin{array}{l}\text { SEMARAK } \\
\text { LELA } \\
\text { SAYANG }\end{array}$ & $\begin{array}{l}\text { SEMARAK } \\
\text { LELA } \\
\text { SAYANG }\end{array}$ & $\begin{array}{c}\text { SEMARAK } \\
\text { LELA SAYANG }\end{array}$ & $\begin{array}{c}\text { SEMARAK } \\
\text { LELA SAYANG }\end{array}$ & $\begin{array}{c}\text { SEMARAK } \\
\text { LELA SAYANG }\end{array}$ & $\begin{array}{c}\text { SEMARAK } \\
\text { LELA SAYANG }\end{array}$ & $\begin{array}{c}\text { KANJURUHAN } \\
\text { PAGI AKHIR } \\
\text { PEKAN }\end{array}$ \\
\hline $\begin{array}{c}08.00- \\
09.00\end{array}$ & $\begin{array}{c}\text { INSPIRASI } \\
\text { KANJURUHA } \\
\text { N (LADIES) }\end{array}$ & $\begin{array}{l}\text { INSPIRASI } \\
\text { KANJURUH }\end{array}$ & $\begin{array}{c}\text { INSPIRASI } \\
\text { KANJURUHAN } \\
\text { (PERMATA } \\
\text { HATI) }\end{array}$ & $\begin{array}{c}\text { INSPIRASI } \\
\text { KANJURUHAN }\end{array}$ & $\begin{array}{c}\text { INSPIRASI } \\
\text { KANJURUHAN } \\
\text { (LIFESTYLE) }\end{array}$ & $\begin{array}{c}\text { INSPIRASI } \\
\text { KANJURUHAN }\end{array}$ & $\begin{array}{l}\text { PENTAS } \\
\text { BINTANG } \\
\text { CILIK }\end{array}$ \\
\hline $\begin{array}{c}09.00- \\
10.00\end{array}$ & $\begin{array}{c}\text { FORUM } \\
\text { KANJURUHA } \\
\mathrm{N}\end{array}$ & (REMAJA) & $\begin{array}{c}\text { FORUM } \\
\text { KANJURUHAN }\end{array}$ & (IVIEL & $\begin{array}{c}\text { FORUM } \\
\text { KANJURUHAN }\end{array}$ & (PSIKOL & $\begin{array}{c}\text { INSPIRASI } \\
\text { KANJURUHAN } \\
\text { (IT) }\end{array}$ \\
\hline $\begin{array}{c}10.00- \\
11.00\end{array}$ & PASKAN!!! & $\begin{array}{c}\text { SOBO } \\
\text { KECAMAT }\end{array}$ & PASKAN!!! & SOBO & PASKAN!!! & PASKAN!!! & PASKAN!!!! \\
\hline $\begin{array}{c}11.00- \\
12.00\end{array}$ & & & & KEC & & & \\
\hline
\end{tabular}




\begin{tabular}{|c|c|c|c|c|c|c|c|}
\hline $\begin{array}{c}12.00- \\
14.00\end{array}$ & $\begin{array}{c}\text { NEWSTAINM } \\
\text { ENT BERITA } \\
\text { SEPUTAR } \\
\text { KAB. } \\
\text { MALANG }\end{array}$ & $\begin{array}{c}\text { NEWSTAIN } \\
\text { MENT } \\
\text { BERITA } \\
\text { SEPUTAR } \\
\text { KAB. } \\
\text { MALANG }\end{array}$ & $\begin{array}{l}\text { NEWSTAINME } \\
\text { NT BERITA } \\
\text { SEPUTAR } \\
\text { KAB. MALANG }\end{array}$ & $\begin{array}{c}\text { NEWSTAINME } \\
\text { NT BERITA } \\
\text { SEPUTAR } \\
\text { KAB. MALANG }\end{array}$ & $\begin{array}{l}\text { NEWSTAINME } \\
\text { NT BERITA } \\
\text { SEPUTAR } \\
\text { KAB. MALANG }\end{array}$ & $\begin{array}{l}\text { NEWSTAINME } \\
\text { NT BERITA } \\
\text { SEPUTAR } \\
\text { KAB. MALANG }\end{array}$ & $\begin{array}{c}\text { LAPTOP } 20 \\
\text { HITS }\end{array}$ \\
\hline $\begin{array}{c}14.00- \\
15.00\end{array}$ & SAMBUNGS & SAMBUNG & SAMBUNGSAR & SAMBUNGSAR & SAMBUNGSAR & SAMBUNGSAR & $\begin{array}{c}\text { SAMBUNGSAR } \\
\text { I }\end{array}$ \\
\hline $\begin{array}{c}14.00- \\
16.00\end{array}$ & ARI & SARI & 1 & I & I & 1 & \multirow{2}{*}{$\begin{array}{c}\text { KARAOKE } \\
\text { DANGDUT } \\
\text { (LIVE) }\end{array}$} \\
\hline $\begin{array}{c}16.00- \\
17.00\end{array}$ & $\begin{array}{l}\text { Mimbar } \\
\text { Islami }\end{array}$ & $\begin{array}{l}\text { Mimbar } \\
\text { Kristiani }\end{array}$ & Lagu Religi & Lagu Religi & Lagu Religi & Lagu Religi & \\
\hline $\begin{array}{c}17.00- \\
18.00\end{array}$ & $\begin{array}{l}\text { JELANG } \\
\text { MAGHRIB }\end{array}$ & $\begin{array}{l}\text { JELANG } \\
\text { MAGHRIB }\end{array}$ & $\begin{array}{c}\text { JELANG } \\
\text { MAGHRIB }\end{array}$ & $\begin{array}{c}\text { JELANG } \\
\text { MAGHRIB }\end{array}$ & $\begin{array}{c}\text { JELANG } \\
\text { MAGHRIB }\end{array}$ & $\begin{array}{c}\text { JELANG } \\
\text { MAGHRIB }\end{array}$ & $\begin{array}{c}\text { JELANG } \\
\text { MAGHRIB }\end{array}$ \\
\hline $\begin{array}{c}18.00- \\
19.00 \\
19.00- \\
20.00\end{array}$ & PASKAN!!! & PASKAN!!! & PASKAN!!!! & PASKAN!!! & PASKAN!!! & PASKAN!!!! & PASKAN!!! \\
\hline $\begin{array}{l}20.00- \\
22.00\end{array}$ & WEST NIGHT & $\begin{array}{l}\text { WEST } \\
\text { NIGHT }\end{array}$ & WEST NIGHT & WEST NIGHT & WEST NIGHT & $\begin{array}{c}\text { MELODY } \\
\text { MEMORY/ } \\
\text { GELORA (LIVE) }\end{array}$ & WEST NIGHT \\
\hline
\end{tabular}

Sumber : Kanjuruhan FM 2018

Keterangan :

1. Semarak : semangat aktifitas pagi, musik \& informasi

2. Inspirasi Kanjuruhan : ladys, remaja, permata hati, medika, lifestyle, psikologi

3. Forum Kanjuruhan : dialog interaktif

4. Paskan : pastikan kanjuruhan

5. Newstainment : berita seputar Kabupaten Malang dan sekitarnya

6. Sobo Kecamatan : informasi lintas kecamatan

7. Gelora \& melody memory : Live

8. Kanjuruhan pagi akhir pekan : rangkuman informasi Kabupaten Malang selama sepekan

9. Sambung Sari : musik campursari tradisional

10. West Night : info musik manca dan film

Hot News: setiap 2 jam sekali / pergantian acara jam 08-16 WIB 


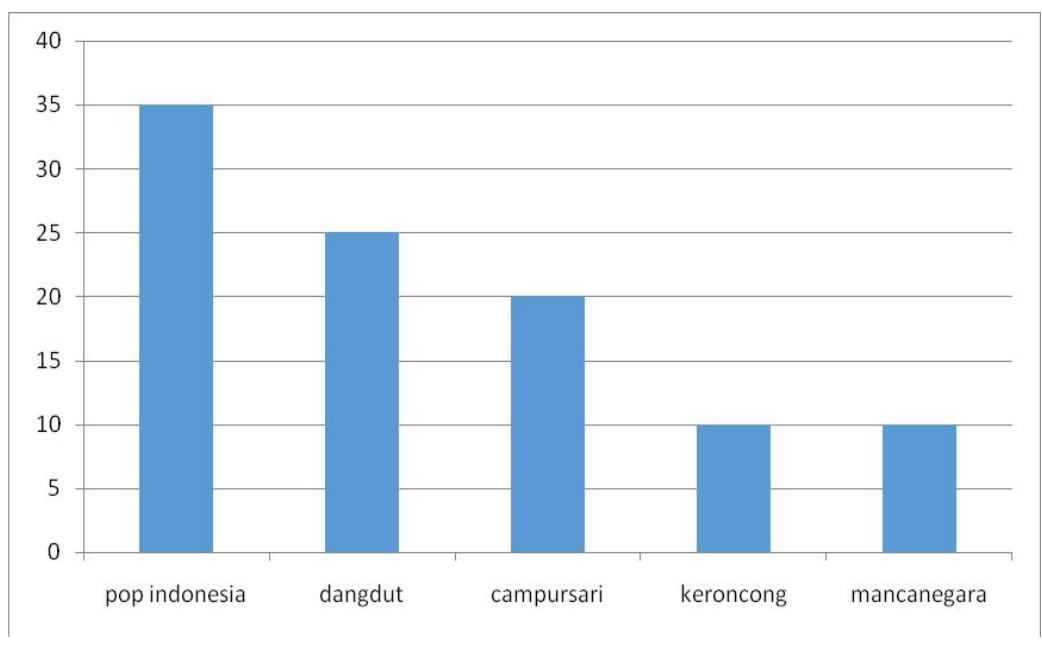

Gambar1. Diagram Genre Lagu

Sumber : kanjuruhan FM 2018

Tabel 4. Segmentasi Pendengar

\begin{tabular}{|c|c|}
\hline Usia & Prosentase \\
\hline 20-29 tahun & $30 \%$ \\
\hline 30-39 tahun & $55 \%$ \\
\hline $40-50$ tahun keatas & $15 \%$ \\
\hline Jenis Kelamin & Prosentase \\
\hline Pria & $50 \%$ \\
\hline Wanita & $50 \%$ \\
\hline Pendidikan & Prosentase \\
\hline SMA & $70 \%$ \\
\hline Perguruan Tinggi & $30 \%$ \\
\hline Pekerjaan & Prosentase \\
\hline Karyawan & $30 \%$ \\
\hline Pelajar & $20 \%$ \\
\hline Mahasiswa & $25 \%$ \\
\hline Ibu Rumah Tangga & $25 \%$ \\
\hline
\end{tabular}

Sumber : data diolah 2018 


\section{B. Format Siaran}

Sebagaimana tujuan pendiriannya dalam rangka memenuhi kebutuhan masyarakat dalam bidang informasi (news and information), pendidikan (education), dan hiburan (entertainnment) sekaligus menjadi alat control sosial. Radio Kanjuruhan FM memiliki peluang besar untuk tumbuh dan berkembang dalam usaha media elektronik.

Tabel 5. Komposisi Siaran

\begin{tabular}{|c|c|}
\hline Komposisi Siaran & Prosentase \\
\hline Berita & $45 \%$ \\
\hline Pendidikan & $20 \%$ \\
\hline Agama & $10 \%$ \\
\hline Hiburan dan Musik & $20 \%$ \\
\hline Informasi & $10 \%$ \\
\hline Jasa Layanan & $5 \%$ \\
\hline
\end{tabular}

Sumber : data diolah 2018

\section{Pembahasan Hasil Penelitian}

Saat ini media tumbuh dalam suatu sistem yang kompleks dan harus bersaing dengan bentuk-bentuk komunikasi yang telah ada guna memperebutkan waktu, perhatian, dan dukungan bila mereka ingin tetap hidup dan memperoleh keberhasilan secara finansial.Pemasaran saat ini sebagai cara untuk menjalankan bisnis. Pemasaran bukan hanya kampanye iklan baru atau promosi, tetapi pemasaran harus menyatu menjadi bagian dari uraian kerja dimana setiap SDM yang bekerja di dunia tersebut disebut penyiaran yang broadcaster. Pendapatan media penyiaran secara klasik didapatkan dari iklan. Pendapatan dari iklan mampu membantu operasional dimedia penyiaran itu sendiri. Dalam kondisi apapun, iklan akan terus tumbuh karena dibutuhkan dan menjadi investasi jangka panjang. Sejalan dengan pertumbuhan media, pertumbuhan belanja iklan tiap media cenderung meningkat. Peluang untuk marketing media penyiaran semakin terbuka sejalan dengan perkembangan media yang diiringi dengan teknologi penyiaran yang semakin pesat.

Radio Kanjuruhan FM salah satu radio yang melakukan beberapa upaya untuk mempertahankan eksistensinya dari berbagai radio. Itu dilakukan untuk menambah jumlah pendengar serta untuk menambah jumlah pengiklan di radio tersebut. Oleh karena itu, sangat dibutuhkan strategi pemasaran yang tepat untuk dilaksanakan. Dari awal berdirinya, Radio Kanjuruhan FM selalu memberikan hal yang berbeda dengan radio lainnya. Dalam perjalanannya Radio Kanjuruhan FM memiliki strategi yang dapat 
mendukung segala usahanya dalam meningkatkan jumlah pengiklan. Hal ini terkait dengan konsep 4P yang telah dikemukakan sebelumnya yaitu, Product, Price, Place, dan Promotion.

1) Produk

Produk yang dimaksudkan disini merupakan program siaran unggulan yang diproduksi oleh Radio Kanjuruhan FM. Salah satu program unggulan yang dimiliki adalah Lela Sayang. Pada program Lela Sayang pendengar bisa langsung request lagu dangdut dan house mix dengan membuka live telepon dan SMS.

2) Price

Harga air time yang ditawarkan oleh Radio Kanjuruhan FM menjadi pertimbangan kepada pengiklan untuk menyiarkan iklannya. Semua radio berlomba-lomba memberikan pelayanan terbaik dan harga terjangkau. Oleh karena itu Radio Kanjuruhan FM menyediakan banyak promo agar pengiklan lebih tertarik untuk beriklan.

3) Penempatan atau positioning

Radio Kanjuruhan FM dihati masyarakat. Program-program yang disiarkan oleh Radio Kanjuruhan FM tentunya harus berkualitas agar masyarakat dapat tertarik untuk mendengarkan. Karena hal itu terkait dengan pengiklanan. Pengiklan sangat mempertimbangkan banyaknya pendengar atau rating pendengar. Terlebih, radio competitor juga membuat program-program yang tidak kalah berkualitas. Adapun 3 program siaran yang dimiliki oleh Radio Kanjuruhan FM yaitu Semarak Lela Sayang, Inspirasi Kanjuruhan, Paskan.

1. Semarak Lela Sayang disiarkan pagi hari pada pukul 06.00-08.00. Ini merupakan program semangat pagi, musik dan informasi. Program ini juga membuka line telepon dan SMS untuk pendengar/masyarakat yang ingin menyampaikan salam dan request lagu.

2. Inspirasi Kanjuruhan disiarkan pukul 08.00-10.00 membahas berbagai persoalan. Seperti lifestyle, psikologi dan masih banyak hal lainnya di masyarakat. Pada pukul 09.00-10.00 setiap hari Senin-Jumat dilakukan dialog interaktif dengan perusahaan atau SKPD yang bekerjasama dengan Radio Kanjuruhan FM. Dalam dialog tersebut juga dibuka line telepom dan SMS untuk berinteraksi secara langsung dengan narasumber.

3. Paskan (Pastikan Kanjuruhan) disiarkan setiap hari pukul 10.00-12.00 dan 18.00-20.00 yang menyajikan informasi berita kehilangan, risalah panggilan, dari Pengadilan Negeri dan Pengadilan Agama Kab. Malang. 


\section{Pemasaran (Promotion)}

Kegiatan pemasaran yang dilakukan Radio Kanjuruhan FM yaitu Advertising, Personal and Direct Selling, Salels Promotion, Event serta Publicity.

1. Advertising. Radio Kanjuruhan FM melakukan berbagai strategi pemasaran sejak awal berdirinya. Wibsite merupakan salah satu cara di Radio Kanjuruhan FM sebagai wadah untuk mempromosikan air time yang ditawarkan ke calon klien.

2. Personal and Direct Selling. Aktivitas yang dilakukan oleh Radio Kanjuruhan dalam melaksanakan strategi pemasaran, yaitu melakukan door to door atau menawarkan secara langsung kepada klien dengan mendatangi perusahaannya.

3. Sales Promotion. Sarana komunikasi pemasaran yang digunakan Radio Kanjuruhan FM dalam melaksanakan aktivitas-aktivitas strategi pemasaran yaitu memberikan promosi, bonus, harga promo atau discount kepada calon pengiklan. Mereka juga melakukan pendekatan melalui kepada calon pengiklan. Jadi mereka tidak hanya melakukan pendekatan melalui iklan saja, tetapi juga melibatkan hubungan emosional.

4. Publicity. Salah satu strategi yang diterapkan Radio Kanjuruhan FM dalam menarik minat calon klien terkait dengan publicity yaitu dengan cara memberikan pelayanan yang baik serta menawarkan konsep atau ide yang menarik, kreatif serta unik. Karena sponsor tertarik dengan materi yang matang. Banyak atau tidaknya sponsor yang masuk pada saat event menentukan keberhasilan event. Serta bagaimana memberikan yang terbaik agar sponsor merasa puas, sehingga nantinya bias melakukan kerjasama lebih lanjut kedepan. Target audience juga sangat dipertimbangkan oleh sponsor. Karena ketika audience yang terlibat cukup banyak akan membuka peluang besar bagi sponsor untuk mengenalkan produknya ke audience.

Dengan berkembangnya teknologi, ekonomi dan pasar mendorong terjadinya persaingan yang ketat dalam peningkatan strategi pemasaran. Persaingan pasar yang ada juga membesar dari tingkat kecil di lingkungan penduduk ke tingkat global. Sehingga strategi yang dibuat harus didukung dengan komunikasi yang memadai dan dapat diterima oleh masyarakat. Hal ini yang dirasakan oleh Radio Kanjuruhan FM karena strategi pemasaran berupa promosi saja tidak cukup. Maka dari itu marketing dan admin selalu berusaha membuat strategi pemasaran untuk dilakukan. Keberhasilan suatu perekonomian secara nasional banyak ditentukan oleh kegiatankegiatan periklanan. Dalam menunjang usaha penjualan yang menentukan kelangsungan hidup produksi perusahaan tercipta lapangan kerja serta adanya hasil yang menguntungkan dari seluruh uang yang diinvestasikan.

Bisnis bertitik mula pada penjualan, itu sebabnya iklan sangat diperlukan. Iklan bukan hanya ditujukan untuk menjual atau membujuk konsumen agar membeli barang demi kepuasan individu. Iklan juga menawarkn jasa. Terkait dengan itu marketing atau pemasaran siaran radio berarti pemuasan kebutuhan pengiklan dan pendengar serta 
pemirsa. Karena iklan adalah bagian dari keseluruhan kegiatan marketing penyiaran.Tujuan utama pemasaran media penyiaran sesungguhnya adalah memiliki pasar, tidak hanya membuat atau menjual suatu program. Ketika media penyiaran memiliki pasar, maka mendapatkan peluang untuk melakukan segala hal. Sebaliknya para pendukung media penyiaran juga dapat melakukan hal sejalan dengan keinginan media penyiaran. Dengan memiliki pasar, radio mendominasi bidang tertentu atau ciri khas yang memiliki nilai jual. Radio Kanjuruhan FM yang memiliki banyak pendengar ini masih memiliki kendala untuk bekerjasama dengan pengiklan. Karena selama ini pengiklan masih segan untuk memasang iklannya dimana Radio Kanjuruhan FM merupakan radio pemerintah yang penyiarannya sesuai protokoler. Meski demikian, hal itu menjadi factor pendukung dari pelaksanaan strategi pemasaran di Radio Kanjuruhan FM Karena dikenal sebagai radio LPPL milik pemerintah daerah. Untuk menjalin hubungan baik dengan para pengiklan Radio Kanjuruhan FM juga melakukan berbagai kegiatan seperti melakukan reportase di event-event yang diselenggarakan baik pemerintah maupun perusahaan. Sebaliknya jika Radio Kanjuruhan mengadakan event, para klien selalu diikut sertakan. Selain itu, Radio Kanjuruhan FM memberikan harga promo kepada klien dan membuat website sebagai bentuk eksistensi di dunia internet untuk meyakinkan para klien.Tidak sampai disitu marketing selalu memberi saran kepada pengiklan untuk memasangkan iklan dengan memberi pilihan seperti membuat spot iklan atau iklan baca (adlip). Bahkan klien juga bisa membawa spot sendiri yang nantinya bisa langsung di putar di Radio Kanjuruhan FM. Selain itu, Radio Kanjuruhan FM melakukan upaya untuk mendapatkan perhatian dari masyarakat yakni bekerjasama dengan perusahaan untuk bergabung dan membuat liputan spesifik untuk menarik simpati, seperti info mengenai orang hilang atau kebakaran. Serta membuat event kegiatan promo atau kegiatan sosial.

Dalam strategi pemasarannya Radio Kanjuruhan FM juga tidak luput dari complain serta kritikan. Tetapi sejauh ini complain sangat jarang terjadi karena Radio Kanjuruhan FM berusaha memberikan pelayanan sebaik-baiknya kepada klien. Selama ini Radio Kanjuruhan FM banyak menyiarkan iklan dari SKPD dan iklan komersil. Salah satu contohnya adalah iklan berupa layanan masyarakat dari pemerintah serta memberikan informasi-informasi tentang kegiatan yang dilakukan oleh SKPD-SKPD terkait. Pemasaran media penyiaran sangat penting untuk melancarkan operasional. Karena pendapatan media siaran akan mengukuhkan kredibilitas radio serta televisi. Dengan demikian visi dan misi media penyiaran dapat diraih. Selain itu, saat ini bekerja dimedia penyiaran bukanlah kerja sambilan. Media penyiaran dapat digunakan sebagai wahana untuk pengembangan karir broadcasting. Bidang ini khususnya pemasarannya bukan hanya terbuka bagi broadcaster, tetapi juga terbuka bagi segala kalangan yang berminat meraih manfaat secara finansial.

Media penyiaran merupakan intuisi public yang terbuka. Artinya, media penyiaran dapat dimiliki dan dioperasionalkan oleh siapapun dari latar belakang Pendidikan, social, dan kelompok masyarakat. Selain itu, dalam perkembangannya 
saat ini, media siaran bukan lagi didominasi oleh perangkat media yang statis. Akan tetapi sudah merambah ke internet jaringan, dan media lainnya. Kordinator, marketing, dan admin merupakan bagian-bagian yang berpengaruh dalam kegiatan pemasaran Radio Kanjuruhan FM. Salah satunya tentang jumlah iklan yang masuk setiap harinnya. Jumlah iklan yang fluktuatif membuat radio selalu berinovasi membuat programprogram yang dibutuhkan oleh pendengar sehingga nantinya juga berpengaruh pada minat pengiklan untuk memasangkan iklannya. Meski demikian tidak dipungkiri dengan berkembangnya zaman, masyarakat lebih tertarik menggunakan internet sebagai bagian promosinya. Hal itu dikarenakan cara yang lebih mudah, respon yang cepat dari konsumen, serta harga pemasangan iklan yang cukup murah menjadi pertimbangan untuk mengiklankan produknya di internet daripada di radio.

Tabel 6. Jumlah Iklan Radio Kanjuruhan 2014-2016

\begin{tabular}{|c|c|c|c|c|c|}
\hline \multicolumn{6}{|c|}{ Total Pemasukan Iklan Radio Kanjuruhan FM } \\
\hline \multicolumn{2}{|c|}{ Tahun 2014} & \multicolumn{2}{|c|}{ Tahun 2015} & \multicolumn{2}{|c|}{ Tahun 2016} \\
\hline Bulan & Jumlah & Bulan & Jumlah & Bulan & Jumlah \\
\hline Januari & 10 & Januari & 7 & Januari & 3 \\
\hline Februari & 8 & Februari & 10 & Februari & 4 \\
\hline Maret & 11 & Maret & 7 & Maret & 4 \\
\hline April & 10 & April & 8 & April & 9 \\
\hline Mei & 5 & Mei & 7 & Mei & 5 \\
\hline Juni & 8 & Juni & 5 & Juni & 6 \\
\hline Juli & 4 & Juli & 4 & Juli & 5 \\
\hline Agustus & 8 & Agustus & 8 & Agustus & 5 \\
\hline September & 6 & September & 7 & September & 13 \\
\hline Oktober & 10 & Oktober & 3 & Oktober & 8 \\
\hline November & 11 & November & 6 & November & 8 \\
\hline Desember & 15 & Desember & 4 & Desember & 13 \\
\hline Total & 106 & Total & 76 & Total & 83 \\
\hline
\end{tabular}

Sumber : Kanjuruhan FM 2018 
Jika dilihat dari jumlah tersebut jumlah iklan di tahun 2014 memang lebih tinggi, karena ada beberapa iklan yang setiap bulannya tetap memasangkan iklan. Sama halnya dengan tahun 2015-2016 dimana ada beberapa iklan yang sama bahkan klien di tahun sebelumnya juga tetap memasang iklan. Untuk itu Radio Kanjuruhan FM juga memberikan program yang berkualitas serta informatif. Seperti program siaran langsung, talkshow, dan laporan kegiatan event baik kerjasama dengan klien atau event yang diadakan Radio Kanjuruhan FM itu sendiri. Tujuannya adalah membuat masyarakat merasa Radio Kanjuruhan FM selalu menyediakan informasi atau berita teraktual yang dibutuhkan. Radio Kanjuruhan FM juga mempunyai strategi untuk menghadapi persaingan dengan radio lain, yaitu dengan mengetahui bagaimana pesaing menyajikan berita dan informasi. Dengan adanya hal tersebut membuat Radio Kanjuruhan FM membuat program yang berbeda untuk menarik minat pendengar. Selain, itu calon klien bias percaya iklan yang akan disiarkan di Radio Kanjuruhan FM didengarkan oleh banyak pendengar dengan harapan pendengar bisa membeli produk atau menggunakan jasa yang telah diiklankan.

\section{E. Analisis Matrik SWOT}

Berdasarkan hasil wawancara dengan kordinator, marketing dan admin dapat diketahui alternative strategi yang digunakan oleh Radio Kanjuruhan FM. Adapun alternative tersebut dapat disajikan pada table berikut :

\section{Tabel 7. Analisis Matrik SWOT}

\begin{tabular}{|c|c|c|}
\hline & $\begin{array}{l}\text { Kekuatan (Strengths-S) } \\
\text { - Radio LPPL Pemkab } \\
\text { Malang } \\
\text {-Mempunyai jangkauan } \\
\text { yang luas } \\
\text {-Adanya Radio Streaming } \\
\text {-Memiliki program- } \\
\text { program yang bagus }\end{array}$ & $\begin{array}{l}\text { Kelemahan (Weaknesses-W) } \\
\text {-Keterbatasan SDM } \\
\text {-Belum maksimalnya pada } \\
\text { bagian teknis }\end{array}$ \\
\hline $\begin{array}{l}\text { Peluang (Opportunities-O) } \\
\text {-Meningkatnya jumlah } \\
\text { perusahaan di Malang } \\
\text {-Teknologi }\end{array}$ & $\begin{array}{l}\text { Strategi SO } \\
\text {-Memperbanyak promosi } \\
\text {-Melakukan inovasi dalam } \\
\text { penyiaran } \\
\text {-Melakukan kerjasama } \\
\text { dengan radio komunitas } \\
\text { dalam mendapatkan }\end{array}$ & $\begin{array}{l}\text { Strategi WO } \\
\text {-Mengadakan training bagi } \\
\text { pegawai } \\
\text {-Menambah jumlah pegawai } \\
\text { sesuai kebutuhan } \\
\text { Meng-upgrade bagian teknis }\end{array}$ \\
\hline
\end{tabular}




\begin{tabular}{|c|c|c|}
\hline & informasi & \\
\hline $\begin{array}{l}\text { Ancaman (Threats-T) } \\
\text {-Persaingan ketat dengan } \\
\text { radio lain } \\
\text {-Banyaknya iklan online }\end{array}$ & $\begin{array}{l}\text { Strategi ST } \\
\text {-Membuat acara yang lebih } \\
\text { kreatif dan menarik } \\
\text {-Memanfaatkan media } \\
\text { internet }\end{array}$ & $\begin{array}{l}\text { Strategi WT } \\
\text {-Harga yang kompetitif } \\
\text { dalam pemasangan iklan }\end{array}$ \\
\hline
\end{tabular}

Sumber : Peneliti 2018

Berdasarkan tabel diatas dapat diketahui secara jelas atas strategi yang dapat digunakan oleh Radio Kanjuruhan FM dalam meningkatkan iklan. Dengan analisis SWOT diharapkan strategi yang digunakan akan lebih tepat dan efektif serta dapat diketahui baik kekuatan maupun kelemahan.

\section{Kekuatan (Strength)}

1. Radio Kanjuruhan FM merupakan LPPL (Lembaga Penyiaran Publik Lokal) milik pemerintah Kabupaten Malang yang memiliki surat ijin siar dari kementrian. Radio Kanjuruhan FM merupakan radio resmi yang dapat dipercaya untuk mempromosikan iklan dari berbagai klien. Karena miliki pemerintah daerah, Radio Kanjuruhan FM juga ikut mempromosikan program-program SKPD sehingga bisa membantu masyarakat untuk mendapatkan informasi secara cepat mengenai layanan masyarakat yang diberikan pemerintah.

2. Selain itu Radio Kanjuruhan FM juga memiliki jangkauan frekuensi yang cukup luas sehingga bisa didengar dibeberapa wilayah di Kabupaten Malang. Karena luasnya jangkauan membuat Radio Kanjuruhan FM memiliki banyak pendengar, hal itu bisa meyakinkan para klien untuk mengiklan produknya. Semakin banyak pendengar, semakin banyak pula konsumen yang mengetahui dan menggunakan jasa atau abarang milik pengiklan.

3. Luasnya wilayah Kabupaten Malang membuat bebrapa wilayah tidak bisa menjangkau frekuensi Radio Kanjuruhan. Untuk itu Radio Kanjuruhan FM memiliki Radio Streaming agar bisa didengar dimanapun pendengar berada. Radio Streaming dibuat sebagai bentuk promosi dan cara untuk mendekatkan diri kepada masyarakat. Dengan adanya Radio Streaming sangat membantu klien untuk mempromosikan produknya hingga luar kota. Bahkan klien juga bisa mengecek secara langsung apakah iklannya dioutar sesuai perjanjian atau tidak.

4. Di Radio Kanjuruhan FM juga memiliki program yang cukup menarik untuk didengar. Salah satunya Program Lela Sayang yang disiarkan setiap hari pukul 
06.00-08.00. Dalam program tersebut pendengar disuguhi konten untuk memberi semangat pagi dengan lagu dangdut house mix dan koplo.

\section{Kelemahan (Weaknesses)}

5. Dengan program yang sudah direncanakan juga dibutuhkan SDM yang memumpuni. Di Radio Kanjuruhan FM masih dibilang belum memadai untuk SDM, karena beberapa karyawan masih merangkap kebagian-bagian lain untuk membantu menjalankan program yang ada. Seperti dibidang marketing dan teknisi. Dengan kurangnya SDM tersebut dapat menghambat proses kerja di tempat tersebut.

6. Selain itu, Radio Kanjuruhan FM juga memiliki kendala dalam teknis yang dapat berpengaruh dengan kualitas radio. Jika radio memiliki suara yang tidak stabil maka akan berpengaruh dengan calon pengiklan yang ragu untuk mempromosikan produknya di Radio Kanjuruhan FM.

\section{Peluang (Opportunities)}

7. Dengan munculnya perusahaan-perusahaan baru di Kabupaten Malang dimanfaatkan Radio Kanjuruhan FM untuk diajak bekerjasama. Radio Kanjuruhan FM menawarkan kerjasama kepada perusahaan-perusahaan baru yang nantinya bisa membantu mengenalkan produk yang dihasilkan kepada masyarakat.

8. Adanya teknologi yang semakin berkembang bisa juga dimanfaatkan Radio Kanjuruhan FM untuk promosi dan menjalankan program-program yang sudah disusun. Selain itu dengan teknologi yang ada bisa membantu radio untuk mengecek berapa banyak pendengar yang aktif mendengarkan radio. Seperti dengan mengirim pesan melalui SMS, adanya laporan berupa angka di computer jika ada yang mendengarkan melalui Radio Streaming.

\section{Ancaman (Threats)}

9. Saat ini sudah banyak bermunculan radio-radio baru yang lebih berinovasi. Bahkan dalam menentukan iklan radio-radio yang ada berlomba dengan memberikan harga yang cukup terjangkau tetapi memiliki frekuensi putar cukup banyak perharinya. Jika Radio Kanjuruhan tidak memiliki program yang bagus maka akan kalah bersaing dengan radio baru terutama radio komunitas yang ada di wilayah Kepanjen.

10.Tidak hanya radio-radio baru, tetapi teknologi yang semakin berkembang dengan memanfaatkan internet sebagai media promosi juga banyak dilakukan masyarakat saat ini. Biaya yang lebih murah, cara pemasangan iklan yang cukup mudah, serta adanya interaksi secara langsung antara konsumen dengan penjual.

Adapun strateginya adalah :

\section{- Strategi SO}

1. Sebagai perusahaan yang bergerak dibidang pemasaran, Radio Kanjuruhan FM harus aktif dalam promosi. Hal itu sebagai bentuk untuk mendekatkan diri kepada masyarakat, serta mengenalkan program-program yang ada. Selain itu, promosi juga dilakukan untuk menarik minat klien agar mengiklankan produknya. Untuk bisa lebih dekat dengan masyarakat dan pengiklan, Radio 
Kanjuruhan FM harus aktif dalam web, facebook, twitter, dan Instagram sebagai bentuk promosi. Selain itu sering mengadakan event juga diperlukan agar masyarakat mengetahui secara jelas profil Radio Kanjuruhan FM. Tidak hanya event yang dibuat sendiri oleh radio, tapi bisa ikut serta dalam event yang diselenggarakan oleh pemerintah dan perusahaan yang sudah bekerjasama dengan Radio Kanjuruhan FM. Disisi lain Radio Kanjuruhan FM harus memiliki brosur dan baliho sebagai cara untuk mempermudah klien mengetahui tentang Radio Kanjuruhan FM.

2. Adanya perubahan-perubahan dalam program sebagai evaluasi juga perlu dilakukan. Perlu adanya perubahan agar masyarakat lebih tertarik untuk mendengarkan. Dengan inovasi-inovasi baru membuat Radio Kanjuruhan FM mampu bersaing dengan radio-radio lainnya.

3. Sebagai radio yang lebih dulu dikenal oleh masyarakat sekitar, Radio Kanjuruhan FM yang merupakan radio resmi ini bisa melakukan kerjasama dengan radio-radio lokal diwilayah Kabupaten Malang. Karena luasnya wilayah Kabupaten Malang cukup sulit mendapatkan informasi dari seluruh wilayah tersebut. Dengan melakukan kerjasama Radio Kanjuruhan FM bisa berbagi informasi serta bentuk kerjasam-kerjasama lainnya.

\section{- Strategi WO}

1. Bagi perusahaan tidak hanya profit yang diperlukan, tetapi SDM yang berkualitas mampu membuat perusahaan semakin maju. Untuk itu dengan adanya training bagi pegawai sebagai bentuk pelatihan agar pegawai lebih memahami pekerjaan yang nantinya akan dilakukan.

2. Jumlah SDM diperusahaan juga perlu diperhatikan, karena saat ini Radio Kanjuruhan FM hanya memiliki 10 pegawai. Sedangkan didalam perusahaan yang bergerak dibidang penyiaran juga dibutuhkan kurang lebih 15 orang untuk membantu program-program yang ada. Seperti bagian marketing, teknisi dan reporter.

3. Meng-upgrade bagian teknis sangat diperlukan. Yang dimaksud disini adalah alat-alat yang sudah lama harus diganti serta melakukan perawatan terhadap alat-alat yang sudah ada secara rutin. Hal itu dilakukan agar radio tetap bisa didengar dengan baik. Meski begitu mengganti alat yang memiliki kualitas bagus tetap dilakukan agar frekuensi radio bisa didengar hampir ke pelosok wilayah.

\section{- Strategi ST}

1. Radio Kanjuruhan FM harus membuat acara yang lebih menarik dan kreatif agar masyarakat semakin suka mendengarkan radio. Seperti, acara live lagu pop khusus untuk remaja, mengadakan komba nyanyi lagu pop, dangdut, campursari dan lagu anak-anak. Selain itu program khusus remaja juga bisa menjadi salah satu alternative untuk menarik masyarakat terutama usia 15-30 tahun yang saat ini sudah jarang mendengarkan radio. Inovasi-inovasi tersebut bisa dikembangkan lagi agar Radio Kanjuruhan FM mampu bersaing dengan radio lalin dan bisa menarik minat pengiklan.

2. Di zaman yang semakin maju, penggunaan internet bukan hal asing bagi masyarakat. Bahkan saat ini, masyarakat sudah dimudahkan dengan adanya 
internet, seperti mencari berita terbaru, informasi tentang jual beli barang atau jasa, bahkan masyarakat bisa mendownload lagu-lagu yang ingin didengar. Dengan seperti itu,radio juga bisa memanfaatkan media internet untuk lebih dikenal oleh masyarakat. Seperti, adanya web yang tidak hanya digunakan sebagai radio streaming tetapi juga bisa digunakan untuk mendownload lagu yang juga diputar di radio, selain itu live delay untuk masyarakat yang ketinggalan program acara yang sudah siar, lebih aktif dalam media sosial, dan membuat aplikasi yang mudah digunakan oleh masyarakat yang ingin mendengarkan radio melalui radio streaming.

\section{- Strategi WT}

Untuk bersaing radio lain, Radio Kanjuruhan FM harus memberikan harga yang kompetitif kepada calon pengiklan. Hal itu dilakukan, karena radio-radio komunitas yang ada di wilayah terutama wilayah Kepanjen memberikan harga jauh lebih murah dengan frekuensi putar lebih banyak perharinya. Dengan memberi diskon putar atau paket harga dibulan-bulan tertentu dapat menarik calon pengiklan. Selain itu paket harga juga diberikan bagi pengiklan yang hanya memasang iklannya tetapi juga melakukan dialog. Bagi pengiklan yang bekerjasama selama satu tahun penuh bisa mendapatkan bonus putar atau diskon dalam harga.

\section{F. Strategi Pemasaran}

\section{Segmentasi Pasar}

Radio Kanjuruhan FM harus mengetahui betul segmen pasar yang dituju. Selama ini penyiaran Radio Kanjuruhan FM ditujukan untuk masyarakat kalangan menengah kebawah atau yang berprofesi sebagai pedagang, petani, tukang becak dan masih banyak lainnya. Segmentasi tersebut dipilih karena mayoritas masyarakat di Kabupaten Malang tinggal dipedesaan dan berprofesi sebagai petani. Dengan demikian Radio Kanjuruhan FM harus memanfaatkan itu dengan cara lebih banyak memberikan informasi-informasi teraktual, memberikan sosialisasi tentang pelayanan masyarakat yang bekerjasama dengan SKPD. Tidak hanya itu, Radio Kanjuruhan FM bisa melebarkan segmen pasar ke semua masyarakat di Kabupaten Malang dengan memberikan informasi tentang lalu lintas, event-event yang diselenggarakan oleh perusahaan dan SKPD. Serta mengajak masyarakat untuk bergabung secara langsung mengabarkan tentang kondisi yang ada di sekitarnya, seperti kebakaran, tanah longsor, lalu lintas dan masih banyak lainnya. Jika Radio Kanjuruhan FM sudah dikenal dan menjadi bagian masyarakat Kabupaten Malang, itu bisa menjadi hal mudah untuk menarik pengiklan agar mengiklankan produknya di radio.

\section{Menetapkan Pasar Sasaran (Market Target)}

Radio Kanjuruhan FM harus melakukan evaluasi kepada para pengiklan denga bertanya langsung kepada klien tentang respon masyarakat atas produk atau jasa yang sudah diiklankan di radio. Hal itu perlu dilakukan agar pengiklan maupun 
Radio Kanjuruhan FM bisa membuat inovasi atau mengembangkan usahanya agar masyarakat tertarik mendengarkan radio dan tertarik menggunakan atau membeli produk yang diiklankan. Radio Kanjuruhan FM juga bisa mengadakan event untuk mengetahui respon masyarakat, apakah segmentasi masyarakat yang sudah direncanakan dapat terwujud atau tidak. Itu bisa dilihat dari masyarakat yang berpartisipasi dalam acara tersebut.

\section{Penentuan Posisi Pasar (Positioning)}

Radio Kanjuruhan FM bisa melakukan inovasi dalam menyampaikan informasi serta membuat iklan yang cukup menarik agar masyarakat lebih yakin saat ingin membeli atau menggunakan produk dari pengiklan. Dengan pembuatan iklan yang lebih nyata seperti saat mengiklankan di televisi bisa menjadi salah satu inovasi agar berbeda dengan radio lain. Selain itu marketing juga bisa berkoordinasi dengan pengiklan ingin seperti apa iklan yang disiarkan, serta memberi materi yang unik dan menarik tetapi tidak menghilangkan karakteristik dari produk yang dihasilkan oleh pengiklan.

Sesuai dengan analisis SWOT dan strategi pemasaran yang sudah dijelaskan diatas, Radio Kanjuruhan FM bisa memanfaatkan teknologi yang ada untuk melakukan promosi, sering mengadakan event yang berhubngan langsung dengan masyarakat, sering melakukan evaluasi tidak hanya mengenai respon masyarakat tetapi juga mengenai harga yang ditawarkan ke pingiklan. perlu adanya kerjasama tim dalam melaksanakan strategi pemasaran. Melakukan study banding dengan radio-radio diluar kota selain untuk menambah ilmu juga sebagai evaluasi kedepannya. Serta adanya pelatihan pegawai dengan mengikuti seminar-seminar mengenai marketing, penyiaran, dan bidang-bidang lainnya yang berkaitan dengan radio.

\section{SIMPULAN}

Hasil penelitian mengenai strategi pemasaran Radio Kanjuruhan FM dalam meningkatkan jumlah iklan dapat disimpulkan sebagai berikut :Strategi pemasaran yang dilaksanakan Radio Kanjuruhan FM adalah bauran pemasaran yang meliputi 4 komponen yaitu, product, price, place, promotion. 4 komponen tersebut memberikan peranan penting dalam menunjang kemajuan Radio Kanjuruhan FM. Berdasarkan Analisis SWOT Radio Kanjuruhan FM bisa memperbanyak promosi, melakukan kerja sama dengan radio local, menambah jumlah pegawai, memanfaatkan teknologi, dan memberikan harga yang kompetitif. Sedangkan dari strategi pemasaran yang diantaranya, segmentasi pasar, menetapkan pasar sasaran (market targetting) dan penentuan posisi pasar (positioning) Radio Kanjuruhan FM bisa mengetahui segmentasi pasar mana saja yang selama ini mendengarkan Radio Kanjuruhan FM. 


\section{Daftar Pustaka}

Fahmi, S. 2015. Analisis Perencanaan Strategi Pemasaran Pada PT. Hapeel Pharmindo, Jurnal Manajemen Bisnis Indonesia, vol.2 No.3, https://doi.org/10.31843/jmbi.v2i3.59.

Kotler, Philip. 2008. Manajemen Pemasaran: Analisis, Perencanaan, implementasi dan Kontrol, Edisi Sebelas. Alih Bahasa, Hendra Teguh. Jakarta: Penerbit PT. Prenhallindo.

Rangkuti, Freddy. 2006. Analisis SWOT Teknik Membedah Kasus Bisnis. PT. Gramedia Pustaka Utama, Jakarta.

Tjiptono, Fandy. 2008. Strategi Pemasaran, edisi 2. Penerbit Andi, Yogyakarta. 